\title{
Democracia: participación y eficiencia ${ }^{1}$
}

Joan Subirats *

\section{Crisis de la relación poder-sociedad}

Debemos destacar la gran proliferación de propuestas que han ido apareciendo en las recientes campañas electorales, y especialmente en esta última, en relación a la necesidad de reformar nuestra joven democracia. Encontramos referencias a cambios en el sistema electoral que buscarían ofrecer más posibilidades de elección por parte de los ciudadanos; se habla de modificar las listas electorales sea en la línea de abrirlas o desbloquearlas, sea en la línea de introducir un sistema de primarias que permita una mayor participación en su composición; se especula sobre la necesidad de introducir límites en la duración de los mandatos; o se crítica el modo excesivamente complejo y poco eficaz en que nuestra Constitución regula la iniciativa popular. En el trasfondo de ese conjunto de propuestas parece latir un mismo sentimiento: no funcionan como debieran los mecanismos de relación entre sociedad y ámbito de representación política.

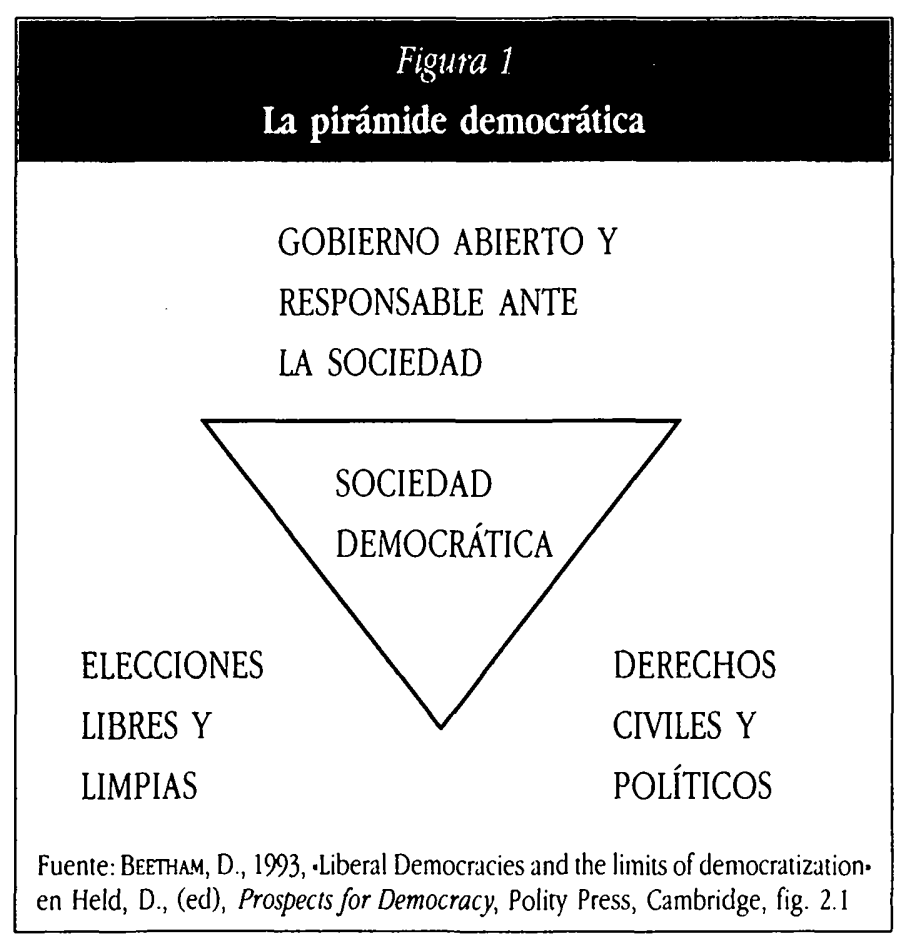

Si intentamos describir de una forma simple los elementos centrales de un sistema democrático, podemos usar la "pirámide democrática. (figura 1) utilizada por BeETHAM en sus conocidos trabajos de auditoría democrática en los que trata de medir el grado de democracia por países. En este artículo nos preocupa, no tanto los aspectos electorales o de derechos, sino sobre todo la parte superior de esa pirámide, en la que se refleja la preocupación por la transparencia y la capacidad de dar cuentas a la sociedad de las acciones gubernamentales. Ser responsable ante los ciudadanos, no sólo implica estar dispuesto a ser periódicamente juzgado por los actos realizados en la función representativa ejercida (elecciones), sino mantener una relación constante entre el elegido y los electores, dando cuenta de lo que se hace o se quiere hacer y oyendo lo que se dice al respecto $^{2}$. No es sólo importante edecidir" en nombre y para los ciudadanos que te han elegido, sino también "explicar" el porqué de esas decisiones, así como "escuchar", recibir "señales", acerca de la oportunidad de esas decisiones y sobre el cómo cambiar o modificar las políticas o programas en curso. Puede afirmarse que todo ello no es más que una manifestación más de la sedicente crisis de la democracia representativa, una muestra más de sus "promesas incumplidas" ${ }^{3}$. Pero, lo cierto, es que la distancia entre esas promesas y la "dura realidad no deja de aumentar. ¿Qué es lo que hace hoy más acuciante ese problema? ¿Hay datos nuevos en esa tradicional tensión entre ideales democráticos y práctica política?

\section{El descrédito de la políica}

En una reciente encuesta del Centro de Investigaciones Sociológicas (CIS) se preguntaba a los ciudadanos con que relacionarían la política de entre un conjunto de vocablos que se les sugerían. Más de tres cuartas partes de los encuestados asociaban política con términos como desconfianza, indiferencia, irritación o aburrimiento. Sólo un $10 \%$ relacionaba política con interés, y sólo uno de cada cien encuestados se refería a la política como asociada a entusiasmo. Pero esa misma encuesta, dedicada al análisis de la llamada cultura política de los españoles, recoge una más que considerable consolidación del sistema democrático en España. A pesar de la falta de tradición democrática en el país, resulta más afianzada que nunca la convic- 
ción de los españoles sobre que la democracia es el mejor de los sistemas de gobierno posible. Como es fácilmente imaginable, los políticos no gozan hoy en España de un gran prestigio. Los encuestados dejan a la profesión de la política en el último lugar de entre el elenco de profesionales que se le someten a juicio, bastante por debajo de los periodistas que ocupan la penúltima posición en ese ranking.

Como en otras encuestas anteriores que el propio CIS y otros institutos de opinión realizaron sobre la misma problemática, los españoles se sienten poco representados por las instituciones democráticas y tienen muy poca confianza en que puedan influir de alguna manera sobre la marcha de los asuntos políticos e institucionales del país. Ese "gran aparato manejado por unos pocos" continúa siendo la visión que cuenta con más respaldos en una sociedad que, como se ha afirmado, practica un cinismo democrático ${ }^{4}$, entendiendo por tal un acusado apoyo al sistema o juego democrático, pero una desconfianza profunda en las formas de jugar, en los jugadores y en sus posibilidades de participación en el mismo.

Pero, ¿para qué preocuparnos de ese tema? Si el sistema democrático goza de un buen nivel de apoyo ciudadano y se consolida su credibilidad como sistema en un país como España con muy poca tradición al respecto, ¿para qué preocuparnos de la lejanía con respecto a las instituciones o de que no nos caigan muy simpáticos los protagonistas o profesionales de ese sistema de gobierno? ¿Tan importante es la política como para que perdamos tanto tiempo en ello? Tenemos muy próximo el ejemplo italiano en el que todo parece indicar que la crisis política es totalmente endémica, los gobiernos no duran más allá de los nueve meses como promedio, han llegado a tener una tercera parte de sus parlamentarios con causas abiertas o indicios de delito y, a pesar de todo ello, el país continúa manteniendo una envidiable capacidad de crecimiento económico y de creatividad en muchos campos. Quizás, como ha apuntado Putnam, es la fortaleza de la sociedad civil de las regiones del centro-norte lo que llegaría a explicar esa capacidad de resistir unos "costes de transacción" que se nos presentan, aparentemente, como muy onerosos, mientras otros afirman que ha llegado la hora de ala política sin los partidos" ${ }^{5}$.

¿Para qué nos sirve la política? Se afirma que la política nos ayuda a resolver conflictos que de otra forma sólo encontrarían solución en situaciones de violencia y tensión social. Podríamos afirmar que buscamos en los gobiernos, en las instituciones políticas respuestas a problemas de carácter colectivo e individual que no encuentran vías de respuesta en el propio funcionamiento del cuerpo social. Para ello, la política y los gobiernos fijan leyes y establecen líneas de intervención y gasto público que han de ser sostenidas con mecanismos de carga fiscal a los ciudadanos, y todo ello requiere sistemas de coerción que aseguren que las leyes se cumplan y los impuestos se paguen. Pero, ¿precisamos aún de esa función complementaria, reparadora? Y en el caso de que entendamos que ello es así, ¿es a través de la actividad política e institucional como más eficazmente lograremos resolver esos problemas colectivos?

\section{Consensos erosionados}

Lo cierto es que los consensos que se habían ido construyendo en torno a estas cuestiones se han ido deteriorando, mientras que el ámbito de intervención pública, y las administraciones que protagonizan ese intervencionismo, han ido pasando de una realidad más o menos homogénea y unificada a una nueva situación profundamente más heterogénea y complicada. Se han multiplicado los niveles de gobierno y se han diversificado, por tanto, poderes y legitimidades. En cada nivel de gobierno se han multiplicado los órganos administrativos, y han proliferado la creación de entes a caballo entre lo público y lo privado en eso que algunos llaman los archipiélagos administrativos". Como es asimismo notorio, se diversifican los campos de actuación e intervención pública, generándose un voluminoso paquete de políticas a cargo de cada nivel de gobierno.

Todo ello provoca un aumento de las contradicciones internas y externas. Contradicciones entre niveles de gobierno que reclaman con ahínco su mejor capacidad, su más genuina legitimación para representar los intereses generales (veáse, por ejemplo, el conflicto entre el gobierno central y las comunidades valenciana y castellano-manchega en relación al paso de la autovía Madrid-Valencia por la zona de las Hoces del Cabriel). Contradicciones entre órganos de una misma administración enfrentados por la defensa de competencias, intereses o clientelas (veáse, por ejemplo, el enfrentamiento entre las consejerías de agricultura y medio ambiente de la Generalitat en relación a la construcción de ciertas infraestructuras, como fue el caso de la presa de Margalef). Contradicciones entre dos o más ámbitos de intervención, lo que da lugar frecuentemente a conflictos entre las políticas de una misma o de diversas administraciones (conflictos, por ejemplo, entre las políticas anti consumo del alcohol de los responsables de sanidad y las campañas de incentivo al consumo de vino de los responsables de las políticas agrícolas; o conflictos entre las políticas antipolución atmosférica de la UE y los vetos de los países productores de vehículos de pequena cilindrada para evitar la obligatoriedad de que tales automóviles incorporen el catalizador necesario para usar gasolinas sin plomo).

De ese cuadro de muy diversos niveles y de esa complicada estructura de órganos, competencias y políticas de intervención, surge una lógica decisional más basada en el compromiso que en una posible racionalidad. No se trata tanto de quién alleva razónn, o quién está mejor legitimado, o quién ocupa una 
posición más fuerte desde el punto de vista formal-decisorio, sino de quién es capaz de construir qué coalición en relación a qué problema ${ }^{6}$.

\section{Un entorno más problemático}

Si hasta aquí nuestro itinerario es puramente descriptivo, y por tanto no hemos hecho más que constatar el aumento de complejidad, tamaño y sistema de toma de decisiones de las administraciones públicas, nuestro problema se agrava cuando relacionamos ese panorama con un entorno que lejos de permanecer estático, se ha problematizado de forma muy notable. En el terreno económico, creando condiciones de insostenibilidad de los niveles de gasto público alcanzados, en un contexto de economía globalizada, y dejando sin alternativas fiables a los equipos de dirección de la política económica en los países avanzados. En el campo de la legitimación de los poderes públicos, aumentando el escepticismo sobre la idoneidad del intervencionismo público para resolver las problemáticas sociales; acentuando la sensación de lejanía entre gobernantes y gobernados; erosionando la credibilidad de las elecciones como mejor mecanismo de producir representación y legitimidad; o denunciando el exceso de politiquería y la necesidad de tener más sentido común para afrontar los acuciantes problemas de la vida en colectividad (con casos como los de Perot, Fujimori, Berlusconi o los más recientes de Forbes o Powell, como ejemplos más conocidos internacionalmente). Mientras los propios problemas se complican, convirtiéndose en más y más insolubles, más globales y complejos, con más actores presentes y con menores posibilidades de resolución clara. Ante ello, no sirven las tradicionales medidas: más dinero, más capacidad de intervención. Hoy la sensación de cansancio fiscal aumenta y la tradicional legitimidad del intervencionismo de posguerra no goza del antiguo consenso. Por todas partes se habla de crisis, pero la misma reiteración del diagnóstico nos hace avanzar poco.

De lo que no cabe duda es que está en crisis la forma de tratar los problemas, de enfrentarse a los mismos. Por una parte, desde una perspectiva interna, se ha ido tendiendo a tratar los problemas de forma excesivamente especializada, usando los canales compartimentados de las estructuras gubernamentales mientras el problema a abordar requería planteamientos más globales o integrales. Por otra parte, y centrándonos en la relación con la sociedad, muchos de los problemas a resolver, por su propio enmarcamiento social, con actores muy diversos en juego, exigirían la superación de los estrechos marcos de las distintas racionalidades técnicas con que los diferentes especialistas los abordan.

Crece el convencimiento de que "así no se puede seguir", y se tiende a buscar respuestas ad boc, del tipo "llaves en mano", que son periódicamente puestas en circulación por consultores y vendedores de soluciones listas para usar. Dejando al margen su mejor o peor presentación o credibilidad y su distinto nivel de aplicabilidad, temas como reingeniería de procesos, planificación estratégica, orientación al cliente, empowerment organizativo, gestión de calidad total, o nueva gestión pública, han ido utilizándose como remedios más o menos mágicos para aliviar los males que padecen las administraciones públicas. En definitiva, se trataría de mejorar la capacidad de dar respuesta de esas administraciones a las demandas de la ciudadanía, y de mejorar también las vías de comunicación entre esas administraciones (como representación organizativa del poder constituido) y la sociedad (que mantiene formalmente su posición de fuente legitimadora de ese mismo poder).

\section{5. ¿Problemas o soluciones?}

Pero, probablemente, el problema no estriba en encontrar "soluciones" más o menos imaginativas o eficientes. Son los protagonismos (técnicos o políticos) en el proceso de la propia definición del problema, lo que está en juego. Es evidente que lo acuciante de los problemas con los que nos enfrentamos nos hace a todos exigir prontitud y eficacia en la resolución de los mismos, pero, lo que no puede ni debe olvidarse es que la sociedad, en sus diversos agregados locales, regionales o estatales, exige asimismo que se cuente con la gente, con los ciudadanos cuando se definan las prioridades o las vías de resolución, o se discutan los efectos que cada alternativa plantea. Queremos muchas cosas al mismo tiempo. Queremos eficacia y rapidez, queremos un cumplimiento escrupuloso de la ley, y queremos ser consultados, queremos participar. He ahí el gran dilema, y la gran dificultad en casar conceptos en los que todo el mundo está de acuerdo, pero que cuando se intentan poner en práctica simultáneamente, sus encajes acostumbran a chirríar.

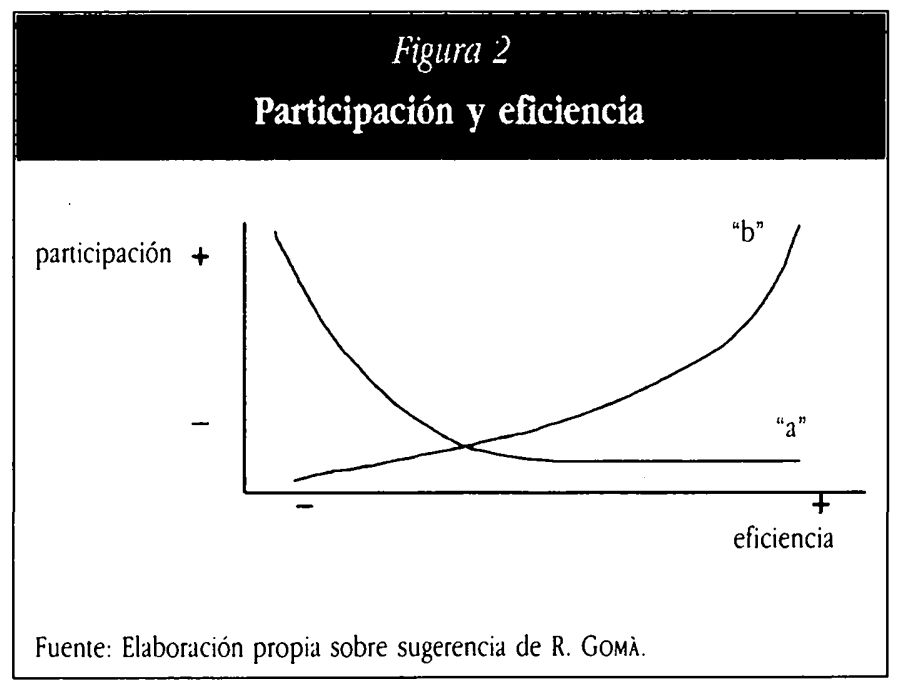


Podríamos afirmar que si en la base del "consenso socialdemocrático" (DAHRENDORF) sobre el que se construyeron los Estados del bienestar de la posguerra, el énfasis se ponía en la eficiencia y se sacrificaba de alguna manera la participación, hoy parece que sin participación real la eficiencia o no es tal, o no compensa los déficit de transparencia y de responsabilidad que acarrea. En la figura 2 hemos intentado reflejar en la curva "a " la idea de que cuanta más presión existía para lograr eficiencia en la acción de gobierno, más parecía deberse sacrificar la participación social en la elaboración e implementación de las actuaciones públicas, mientras que ahora la curva "b" indica el cambio de acento que se viene produciendo, cuando sólo a través de acentuar la transparencia y la participación social se lograrían políticas eficientes a medio y largo plazo.

¿Como resolver el aparente dilema planteado entre eficiencia y participación? Lo cierto es que no hay soluciones disponibles y aplicables al momento. Como dice Crozier en su último libro, hemos de olvidarnos de las soluciones y pensar más en los problemas. $Y$ hacerlo transformando nuestra democracia de acceso hacia una democracia de deliberación y debate ${ }^{7}$, entendiendo que no se trata de consultar a la gente que opina sobre lo que nosotros hemos decidido, sino de incorporar la opinión y las razones de los actores sociales implicados en la propia determinación de los problemas a solventar. Pero incorporando a la discusión no sólo los temas relacionados con el "cómo", sino también dilucidando los respectivos protagonismos de administraciones y actores en el tema, o planteándonos directamente la pregunta de si necesitamos o no a esas administraciones.

Lo que parece claro es que continúan existiendo en nuestras sociedades problemas que difícilmente pueden dejarse a la libre actividad del mercado. MAJONE menciona temas como los medioambientales, de regulación social, de protección de los consumidores, de gestión de riesgos o de seguridad en el trabajo, como ejemplos claros al respecto ${ }^{8}$. Y ante este tipo de cuestiones no pueden plantearse perspectivas exclusivamente centradas en problemas de eficiencia: cómo hacer las cosas más rápidamente y con menos costos económicos. A pesar de que esa perspectiva técnico-económica sea hoy la predominante, es innegable que desde un punto de vista sociopolítico, las preocupaciones derivan más hacia temas relacionados con la equidad: quién gana y quién pierde en cada caso, en cada posible solución. La eficiencia del mercado tiene claras debilidades "morales", ya que muchas veces sus soluciones, si bien pueden ser consideradas eficientes, resultan injustificables desde otras perspectivas, y si son justificables pueden no ser eficientes. La no justificabilidad vendría determinada por razones como la equidad o la democracia9.

\section{Autoridades independientes, eficiencia y control}

¿Cómo combinar ambas exigencias? Si existiera una total coincidencia de las partes (decisores, técnicos, implicados,...), tanto sobre el problema a solventar como con las soluciones podríamos pensar que ello resolvería el problema, pero una situación de este tipo es más bien excepcional, y lo que encontramos generalmente es un escaso consenso tanto desde una perspectiva estrictamente técnica como desde una perspectiva social sobre el caso que se discute ${ }^{10}$

Por otro lado, desde una perspectiva eficientista, es evidente que esa búsqueda del mayor consenso posible, esa búsqueda de la unanimidad, puede resultar un proceso excesivamente costoso desde el punto de vista temporal y procedimental. Los costes de transacción pueden ser vistos como excesivos, cuando lo que prima es la necesidad de resolver la situación cuanto antes. Es desde esta perspectiva que se han ido buscando alternativas en fórmulas organizativas más ágiles, que combinen una cierta legitimidad con un cierto aislamiento del debate pluralista. Estamos refiriéndonos a ese conjunto de agencias, tribunales, o autoridades administrativas independientes, que han ido proliferando o que han revivido como instrumentos de resolución de conflictos o de regulación de sectores específicos. (podríamos citar ejemplos como los de la Comisión Nacional del Sector Eléctrico, el Tribunal de Defensa de la Competencia, el Tribunal de Disciplina Deportiva, la Comisión de Valores, o en otro contexto la proliferación de ombudsman en entidades públicas o privadas).

¿Cuál es la peculiaridad de este tipo de organismos? Se trata de entes que basan su capacidad de intervención en determinado ámbito en su profesionalidad, competencia e independencia. Su autoridad reside no en su representatividad o consenso, sino en su expertise, su prestigio técnico, y su presumible independencia frente a intereses y partidismos. Aseguran, por otro lado, la continuidad de sus actuaciones al margen de los avatares democráticos. Su autonomía y su conocimiento técnico de la problemática en que intervienen, les faculta a decidir con prontitud y eficacia.

Podríamos plantearnos si esa independencia y autonomía en relación a intereses y autoridades políticamente representativas, no les hace asimismo menos controlables, menos responsables ante la sociedad en general. Estaríamos ante un caso similar al planteado en relación a las instituciones europeas, en las que muchas veces su aislamiento de los canales de control democrático de cada país, les permite establecer directivas europeas que van bastante más allá de lo que han ido en ese 
campo las normativas de cada país de la UE, o al menos, de buena parte de ellos. Es ese edéficit democrático', se afirma, lo que les permitiría innovar más allá del medio comun denominador de los quince países. En el caso que estamos analizando, la situación parece paralela: rapidez, eficacia y decisiones que van más allá del puro compromiso entre intereses, a cambio de perder capacidad de control y de transparencia democráticas. Desde otra perspectiva ${ }^{11}$, se ha mencionado la tendencia a construir :Democracias de delegación', aludiendo a gobiernos o instituciones que si bien han sido elegidas por los ciudadanos, se -separan. después de ellos, restringiendo enormemente su accountability, pero asegurando eficiencia y capacidad técnica, partiendo de la hipótesis que las cosas las han de decidir aquellos pocos que entienden de ello.

Volvemos, por tanto, a tener planteado el posible conflicto entre eficiencia y participación. ¿Deberíamos renunciar a la eficacia si queremos mantener intactos los principios de control democrático de los decisores? ¿O, más bien la presión acuciante y la complejidad de los problemas con que nos enfrentamos nos deberían hacer priorizar eficacia y eficiencia a accountability? ¿No es muchas veces el miedo al conflicto lo que conduce a buscar caminos alternativos, como los mencionados, para conseguir decidir o hacer, sin estar sujeto al contraste más o menos conflictivo de los propios puntos de vista? Pero plantear así el tema es no tener en cuenta o minusvalorar la capacidad integrativa de las democracias modernas. La especificidad de la democracia reside en su capacidad de legitimar el conflicto, el disenso, y su rechazo a la supresión del mismo a través de mecanismos autoritarios ${ }^{12}$. Cuando hablamos de este tipo de autoridades o tribunales independientes, hacemos referencia a una "autoridad" distinta de los autoritarismos políticos, que reside en su expertise, pero es esa diferencia la que permitiría superar el conflicto y plantear soluciones "neutrales" u "objetivasn. Una democracia activa exige debate sobre alternativas. Es tan importante el consenso como el disenso. Necesitamos el consenso para hacer funcionar nuestras instituciones representativas, pero el disenso sobre los valores que esas instituciones han de servir, las distintas interpretaciones sobre esos valores es también intrínseco a la democracia.

Ante ese dilema sería importante buscar nuevas vías que dieran más transparencia a los procesos de decisión, posibilitando mayores niveles de consulta, de debate, y de participación social. No tanto para sustituir las actuales vías de decisión colectiva en las instituciones representativas, como para permeabilizarlas y hacerlas más sensibles a las "señales" que se les lanzan desde la sociedad.. El objetivo es abrir espacios para que exista confrontación sobre los valores politicos en presencia, entendidos como interpretaciones no coincidentes en una tradición democrática ampliamente compartida.

\section{Democracia de acceso, democracia deliberativa}

Porque lo cierto es que hemos ablindado nuestra democracia, ritualizándola, convirtiéndola en una democracia básicamente de acceso. Las elecciones abren de cuando en cuando un espacio en el que es posible recuperar en cierta forma el debate, pero de hecho se trata de un debate absolutamente vinculado al acceso al poder. No importan tanto los problemas o las soluciones, como el quién ejercerá el poder. Se nos ha ido muriendo en el camino la democracia de debate, de deliberación, y ello tiene consecuencias en la percepción de falta de legitimidad de ciertas decisiones de los poderes públicos, de los que si bien nadie discute su representatividad, sí se discute su falta de sensibilidad para contar con las opiniones de los afectados en temas conflictivos. Ser elegido en unas elecciones por la mayoría que sea, o contar incluso con la unanimidad de los cargos electos de una institución, no implica necesariamente tener carta blanca para actuar sin tener en cuenta que ciudadanos y grupos pueden querer ser escuchados y que, muchas veces, sus opiniones pueden evitar, de ser recogidas con la anticipación necesaria, ulteriores y más graves problemas.

Estamos asistiendo a una cierta proliferación de referéndums en todos los niveles de gobierno ${ }^{13}$, que sirven para contrastar la opinión de los ciudadanos en temas considerados polémicos o que la prudencia políica aconseja que no sean despachados con una votación ordinaria en una cámara parlamentaria o pleno municipal (desde los casos de la ratificación del Tratado de Maastricht en Francia o de la OTAN es España, hasta los numerosos casos de consultas municipales en temas localmente peliagudos). No es que la institución del referéndum sea un ejemplo cristalino de participación directa y popular. Todos sabemos de sus grandes posibilidades de mediatización y manipulación, pero su creciente uso en países de raigambre democrática podría ser una nueva muestra de las insuficiencias que las vías tradicionales manifiestan. En cierto modo se buscan salidas que permitan abrir el debate a la sociedad, permitir que se escuchen todas las voces, sin que ello implique necesariamente el no poder llegar a conclusiones o decisiones.

Cuanto mayor es el ámbito de intervención de las administraciones públicas y más complejos los temas a resolver, más difícil resulta articular a los intereses en presencia usando los mecanismos convencionales con que la democracia representativa ha ido enriqueciéndose. Perentoriedad en la intervención, búsqueda de eficiencia, segmentación técnica, son elementos que conducen a buscar el camino más corto o la presentación de ciertas soluciones como las únicas posibles, sin que esa convicción haya calado en los actores en presencia, y sin que, por 
tanto, exista una clara legitimación sobre la idoneidad de una solución que acaba siendo percibida como impuesta.

La democracia española se constituyó en un momento en que se prefirió fortalecer los instrumentos tradicionales de participación política (elecciones y partidos), antes que favorecer otros mecanismos, quizás más ágiles, flexibles y accesibles de participación política al margen de los cauces mencionados. Así, la iniciativa legislativa popular se configuró de manera que fuera difícil su activación y su posterior repercusión, y se evitó la instrumentación de un mecanismo como el referéndum abrogativo o propositivo. Los partidos quizás se vieron fortalecidos por esas cautelas, pero a la postre casi todos reconocen los problemas que apuntábamos al inicio de este artículo: la importante y creciente distancia entre sociedad y sistema político (de representación). Ello no implica que los partidos políticos nos resulten ya inservibles desde la óptica participativa que aquí dibujamos, pero hemos de reconocer sus actuales insuficiencias.

¿Por qué ante nuevos problemas, no plantearse, no explorar nuevas vías que combinen o intenten combinar participación con eficacia, recuperándose así el valor deliberativo y de contraste de ideas de la democracia? Todo aquello a lo que nos hemos aferrado con fuerza en estos años, después de tanto predominio del autoritarismo y la intransigencia, parece ahora ser insuficiente o poco capaz de reflejar la pluralidad y la riqueza de matices de una sociedad que se ha hecho más madura y más "respondona". Las sociedades piden respuestas a sus problemas, pero piden asimismo ser consultadas. Exploremos nuevas vías, con cautela si se quiere, sin renunciar a lo que ya tenemos, pero conscientes de las limitaciones de lo que actualmente tenemos.

\section{Elementos de innovación democrática}

Las alternativas pueden ser de muchos tipos. Lógicamente, cuanto más porcentaje de población queramos implicar en los procesos consultivos y participativos, más peligrará la capacidad deliberativa de las opciones. Y cuantos menos ciudadanos participen realmente en las consultas, menor capacidad representativa obtendremos. Pedir que se agilizen y se activen viejas y nuevas formas de participación, no implica la voluntad de convertir a los representantes en una especie de delegados o comisarios de los ciudadanos. Los ciudadanos tienen y expresan diferentes opciones, valores e intereses, y sus representantes políticos han de buscar el equilibrio entre esas diferentes aproximaciones a partir de su propio sistema de valores. Muchas veces los ciudadanos discuten con vehemencia sobre las distintas definiciones de problema que rodea una situación no deseada socialmente que acabará provocando la actuación de los poderes públicos. Son los actores más directamente político-representativos los que acabarán decantando ese debate hacia una definición-de-problema-solución. Su capacidad de captar e implicar en esa alternativa a la mayor parte de ciudadanos e intereses es lo que proporcionará mayor o menor legitimidad y factibilidad a la actuación administrativa posterior.

No podemos confundir esta llamada a innovar los mecanismos de participación democrática con una organización de actos más o menos genéricos en los que los representantes explican sus programas de intervención a los ciudadanos. Ese tipo de actos, a no ser que estén directamente relacionados con un tema conflictivo, lo que genera otro tipo de relación, acostumbran a ser vistos como frustrantes por ambas partes, ya que de hecho se trata de sesiones de características básicamente informativas, en las que no se produce la bilateralidad comunicativa, y donde predomina la apatía. Nos referimos a mecanismos o ejemplos de innovación en la participación democrática que buscan combinar información, deliberación y capacidad de intervención de los ciudadanos en los procesos decisionales, sabiendo que no existe una solución ideal al conflicto ya mencionado entre racionalidades técnicas y económicas, participación popular y rol de las instituciones democráticas responsables últimas ante la sociedad de las decisiones a tomar.

Podríamos distinguir diferentes vías o mecanismos de participación, diferenciando: aquellos que pretenden básicamente conocer la opinión de los ciudadanos unas vez éstos estén ampliamente informados del problema o problemas planteados y de sus posibles alternativas; aquellos en que se quiere implicar a las comunidades en los procesos decisionales de las instituciones representativas; y aquellos que buscan la presencia directa de los ciudadanos en el proceso decisional ${ }^{14}$.

\section{a) La información y el debate como fundamentos de la participación}

Nos referimos en este apartado a experiencias de participación e implicación ciudadana que han buscado ir más allá de las entidades, grupos o asociaciones que, en defensa de sus intereses, intervienen o pretenden intervenir en un proceso decisional específico. Pero que, al mismo tiempo, han buscado un tipo de participación popular que superara los límites marcados por la utilización de encuestas o consultas puntuales. En el primer caso, las opiniones de los actores en el proceso (stakebolders), siendo absolutamente importantes y relevantes, se entenderán siempre mediatizadas por la defensa de sus intereses. En el segundo caso, al margen de la mayor o menor representatividad de la encuesta o consulta realizada, lo que 
obtenemos al final no es una opinión basada en la consideración sobre las distintas alternativas en juego, sobre las implicaciones o consecuencias de cada una de ellas, sino un conjunto de porcentajes (de votos) que indican la mayor o menor inclinación popular sobre esas alternativas. Buscamos ir más allá de los intereses o los votos, buscamos deliberación. Buscamos contraste público de ideas sobre los temas objeto de controversia.

Existen diversas experiencias al respecto: los jurados de ciudadanos o núcleos de intervención participativa ${ }^{15}$, las encuestas deliberativas (Deliberative Opinion Polls) ${ }^{16}$, o las conferencias de consenso o grupos de mediación ${ }^{17}$, entre otras. Todas ellas tienen en común la voluntad de mezclar aportaciones basadas en los conocimientos técnicos y aquellas basadas en la defensa de los intereses sociales en presencia, con las fundamentadas en el sentido común y las experiencias personales de los participantes. Se busca en la deliberación el formar una opinión responsable, informada de pros y contras, consciente de las consecuencias de las alternativas en conflicto, sin que ello implique necesariamente el llegar a una solución ‘correctan. La decisión continúa compitiendo a las instancias representativas, que pueden ver más legitimada su decisión si ella coincide sustancialmente con las resoluciones de los núcleos participativos creados o con las opiniones surgidas de las otras vías de deliberación y estudio mencionadas.

Para evitar los problemas ya mencionados relativos a la dificultad de contar con la opinión de todos los ciudadanos, lo que conduciría al bloqueo de esta vía o a volver a las instituciones de carácter representativo, en algunos casos se usan mecanismos de selección aleatoria de los ciudadanos a implicar en el proceso de deliberación, buscando así una muestra representativa de la comunidad afectada por la decisión a tomar. Se acerca así a la institución del jurado, pero usada en un contexto de discusión de políticas.

«Un pequeño grupo de ciudadanos, representando al público en general, se reúne para explorar una cuestión específica relativa a una política concreta. Los diversos implicados presentan sus informaciones y alegaciones ante ese jurado, que examina sus puntos de vista y les cuestiona. Los jurados deliberan sobre los problemas planteados, y hacen públicas sus conclusiones ${ }^{18}$

Este tipo de jurados de ciudadanos, células de planificación, o núcleos de intervención participativa, se han usado sobre todo a nivel local, y han servido no para reemplazar a los decisores, sino para informarles de los puntos de vista meditados e informados, de un grupo reducido de ciudadanos escogidos al azar, que se reúnen durante varios días, en los que tienen acceso a toda la información disponible sobre el caso. Su uso ha sido importante en Alemania, patrocinado por la Universidad de Wuppertal, y en ciertos casos derivados de ese centro en
Guipúzcoa en España, y ha sido promovido en los Estados Unidos por el Jefferson Center for New Democratic Processes, en Minneapolis.

En el caso de las encuestas deliberativas, nos encontramos con un mecanismo que nos puede permitir conocer la opinión informada de un grupo numeroso de ciudadanos, sobre cualquier tema. FISHKIN, quién ha patrocinado ese mecanismo, lo ha usado experimentalmente en los procesos de selección de candidatos a las presidenciales en los Estados Unidos o en discusiones públicas sobre ley y orden en Gran Bretaña. Se trata también de reunir una muestra de los votantes, informarles detalladamente de los datos del problema planteado, para posteriormente pedirles su opinión en una encuesta diseñada al respecto. Se trataría de opinar después de conocer o saber, y no antes como acostumbra a suceder en el sistema de encuestas tradicional ${ }^{19}$. Aquí el número de personas implicadas es mayor, con lo que la capacidad de penetrar en el tema puede ser menor, y vuelve a plantearse, como en el el caso anterior, el problema del sesgo o bias que puede producirse en la selección de la información o de los informantes al grupo de ciudadanos escogidos.

Las llamadas conferencias de consenso buscan asimismo el conocer la opinión informada de la "gente común. sobre un tema rodeado de una cierta polémica, e intenta por tanto confrontar las lógicas técnicas o científicas, y las derivadas de la defensa de intereses con la opinión de la ciudadanía en general o de parte de ella. En este caso, la incorporación de los participantes no se produce de forma aleatoria, sino que se realiza a través de la autoselección que se da al responder a una serie de anuncios pidiendo a aquellos ciudadanos interesados en el tema que participen. A partir de ahí el sistema de trabajo varía un poco de los anteriores sistemas, pero su base es la misma. Se ha usado en Dinamrca en relación a un tema de polución atmosférica, en relación al posible uso de tarjetas de identidad electrónicas, y en Gran Bretaña en la discusión sobre plantas biotecnológicas ${ }^{20}$.

Los grupos de mediación se circunscriben mucho más a formas de resolución de conflictos, en las que se busca el implicar en la elaboración de la solución o compromiso final a los propios intereses y grupos afectados. Se acerca a los otros ejemplos antes mencionados en que lo que se persigue no es sólo un voto de mayoría o una forma de solventar el tema de manera eficiente y rápida, sino que la decisión a la que se llegue, o el informe que se emita para que la institución representativa ejerza su potestad, surja de una profunda y completa deliberación sobre las alternativas en juego y del contraste entre las posiciones de partida. Ello puede darse a través de mecanismos de facilitación, mediación o arbitraje no obligatorio. Pero, lo importante es que la comunicación entre las partes exista y se cree el clima necesario para que la "salida" sea factible ${ }^{21}$. 


\section{b) Implicar a las comunidades}

Crece la sensación de que sin vías en que las diversas comunidades de afectados en la resolución de un problema puedan verse implicadas en la elaboración de la decisión, esa decisión tendrá muchas posibilidades de que no pueda ser implementada, total o parcialmente. No se trata de presentar este tema como una verdadera innovación, ya que de hecho este es un campo en el que, sobre todo a nivel local, se han dado variadas y diversas experiencias.

Las vías o marcos de implicación de esas comunidades pueden articularse desde el ámbito sectorial en que esas políticas locales se mueven, o desde el ámbito territorial que se ve afectado por esas políticas. Desde la segmentación territorial. se dan más posibilidades de convertir a esos fórums de ciudadanos en una forma de discusión y debate organizado del trabajo de los ayuntamientos, pudiéndose vincularse este tipo de fórums al desarrollo de formas de descentralización municipal. El peligro se daría al marginar intereses que no fuesen suficientemente representativos o importantes a nivel territorial, pero cuya relevancia en políticas sectoriales fuera significativa. La combinación, por tanto, de fórums de ciudadanos vinculados territorialmente con fórums organizados sobre temática sectoriales sería necesaria.

¿Cual sería la real implicación de estos fórums en los procesos decisionales? Recordemos lo que decíamos al principio de estas líneas. El poder de decidir ha de ir acompanado de la capacidad de explicar y de la voluntad de escuchar o recibir señales del entorno. Esas experiencias refuerzan esa capacidad de explicación y de auscultación. Mantienen los canales de comunicación abiertos, y permiten que la capacidad de decisión se ejerza con mayores dosis de información, legitimación y de anticipación de problemas. Y puede al mismo tiempo, implicar a esos ciudadanos y a sus comunidades en vías y mecanismos de control sobre los procesos de implementación y de análisis de los efectos producidos.

\section{c) Canales de democracia directa}

Si a lo largo de estas páginas algo ha quedado claro, probablemente sea la voluntad de contribuir a mejorar los canales de comunicación poder político-sociedad y el funcionamiento de la democracia representativa, incrementando las posibilidades de participación de los ciudadanos en los asuntos y las decisiones públicas. En esa línea, no es inoportuno plantearse las potencialidades participativas que ofrecen algunas vías de democracia directa. No tanto como complemento de la democracia representativa, sino como expresión puntual del cuerpo social ante determinadas cuestiones.
Hemos ya mencionado anteriormente la institucion referendaria como la vía más clásica de democracia directa. Y hemos ya puesto de manifiesto, de pasada, sus inconvenientes derivados de su relativa facilidad de manipulación y confusión en la presentación de alternativas ${ }^{22}$. Pero no, por ello, hemos de olvidar su fecundo y renovado uso en la esfera local ${ }^{23}$, en países como Suiza, Estados Unidos o Gran Bretaña. De hecho, puede resultar positivo su uso para expandir el debate y la deliberación de ciertos temas fuera de los confines de las instituciones políticas, y para mejorar la propia calidad de una discusión que sólo se produzca en los confines de la representatividad institucional.

Lo cierto, es que la efectividad de los referéndums como instrumento de mejora de las potencialidades de participación democrática en los procesos decisionales públicos, sólo puede aceptarse si se cumplen algunas condiciones. Esas condiciones afectan tanto a la issue o tema objeto de controversia (su posibilidad de ser más o menos aislado en relación a otros problemas), como a la capacidad de transformar el tema en un objeto de debate y discusión de la población (información suficiente, disponible y circulante), y la posible reducción de la gama de alternativas al binomio de respuestas que tradicionalmente maneja el referéndum.

De esta forma se puede atemperar o restringir las grandes posibilidades de manipulación, simplificación excesiva e intoxicación que esa institución referendaria conlleva, como de hecho bien conocemos en nuestro país. Por otra parte, cabe recordar que, de hecho, la participación en los referéndums acostumbra a ser más baja que la participación popular en las elecciones (ver figura 3), como si el ciudadano prefiriera delegar la responsabilidad final sobre los problemas sociales a aquellos "encargados" del tema, más que ser requerido directamente a concluir el debate sobre lo considerado como más conveniente.

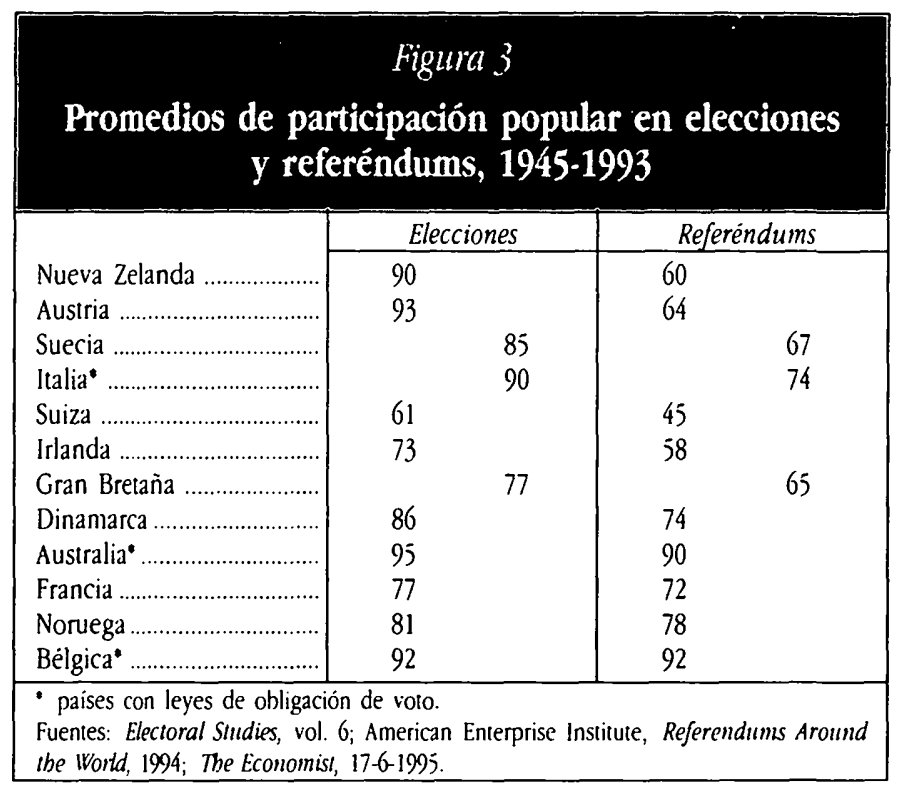


No podemos cerrar este artículo sin referirnos, aunque sea de forma muy sintética, a las nuevas potencialidades que las telecomunicaciones plantean en el funcionamiento de nuestro sistema democrático. Así, ha sido objeto de notable atención el caso de Columbus (Ohio) y su sistema interactivo de televisión por cable, que permite a todos sus habitantes participar a través de un sistema de cinco botones multialternativas en consultas puntuales que les puede plantear la municipalidad. En otros casos, se han utilizado sistemas de cableado televisivo, para organizar debates entre responsables de instituciones políticas y amplios grupos de ciudadanos, con presentación de alternativas, debate entre diversos actores, en que se ha pedido a dichos ciudadanos el que participaran en consultas interactivas sobre cuál de las opciones presentadas les parecía más conveniente (caso del Estado de Oregón y el debate sobre prioridades de gasto público), sin que ello condicionara de forma total a la institución representativa promotora de la experiencia.

La gran expansión de las vías de conexión electrónica (Internet y similares) ha multiplicado las "ventanas" por las que las diversas instituciones representativas permiten el acceso a sus ciudadanos, para que depositen sus mensajes, ideas o protestas, o simplemente para que tengan acceso a una inmensa base de documentación administrativa (aunque no siempre esa mayor facilidad de acceso resuelve el problema de la opacidad de su lenguaje y presentación). Se generan fórums de ideas en ciertas cuestiones, pero aún hay poca claridad en relación a la incardinación de esos nuevos instrumentos de consulta y participación en los procesos decisionales públicos. De hecho, la facilidad con que podrán en el futuro producirse este tipo de consultas, pemritirá su gran proliferación, acortándose notablemente la hoy ya tenue distancia entre el mundo de las encuestas y unos referéndums cada vez más usados.

Por otro lado, los hay menos entusiastas acerca de los usos y potencialidades de este tipo de avances en comunicación, dada su posible utilización abusiva por parte de los grandes y no tan grandes grupos de intereses o lobbies, que podrían (como de hecho ya hacen) "bombardear" a las instituciones representativas, mediante la movilización electrónica de sus afiliados o simpatizantes, a través de faxes, llamadas teléfonicas, y uso de módems, dirigiendo sus mensajes a los medios de comunicación o directamente a los representantes políticos ${ }^{24}$.

El problema, como hemos ya mencionado con el tema referéndums, es la enorme posibilidad de manipulación que este tipo de -democracia instántanea॰ permite. No se dan los supuestos de enfriamiento ', de reflexión desapasionada, de contraste cara a cara, que se dan en las instituciones representativas, con clara asignación de responsabilidades sobre quién y como toma decisiones. Preguntas como achan de recibir asistencia sanitaria los emigrantes ilegales?, ¿hemos de reducir nuestras prestaciones sociales por culpa de las previsiones del Tratado de Maastricht?, ¿debemos condenar a muerte al asesino recién detenido?, no son fáciles de plantear y debatir en un entorno en el que la reflexión y la deliberación tienen dificultades para poderse desarrollar.

\section{Conclusión}

En este artículo se han expresado ciertos problemas, ciertas experiencias y ciertas perplejidades. No hay respuestas o soluciones claras. En el mismo se mantiene la convicción de que sólo construyendo mecanismos democráticos que permitan decidir con rapidez y eficacia, pero también mecanismos que permitan explicar a la ciudadanía y escuchar sus opiniones y tener en cuenta las mismas, será posible mantener en pie unas instituciones democráticas que se han ido convirtiendo en material sensible. En nombre de la eficiencia, de la crítica a la politiquería, o a la vulnerabilidad de esa democracia frente a la potencia de los intereses organizados, se pueden abrir las puertas a peligrosos experimentos autoritarios, revestidos de simple sentido común o de objetivismo técnico. Todo ello no puede conducir a encerrarnos en la defensa numantina de unas instituciones y unos mecanismos de decisión representativa que se obstine en no experimentar nuevas vías de participación y deliberación popular. No habría nada más peligroso que ello. No es ésta, por tanto, una conclusión, sino una invitación a mirar con nuevos ojos una vieja y querida realidad.
- Catedrático de Ciencia Política y de la Administración. Universidad Autónoma de Barcelona.

1 Los primeros borradores de este articulo han sido presentados en conferencias en la UIMP de Santander (agosto 1995), y en unas jornadas sobre participación popular en el patronat Flor de Maig de la Diputación de Barcelona (enero de 1996). Quisiera agradecer los valiosos comentarios recibidos de Ricard Gomà y Quim Brugué, profesores de la UAB.
2 Vid. John Stewart, Innovation in democratic practice in local government., en Policy and Politics, n. 1, vol. 24, enero 1996, pp. 17-28.

3 En expresión de BubBio en su ya clásico libro Il fuluro della democrazia, Einaudi, Turín, 1984, pp. 8 y ss.

- En expresión de J. M. Maraval. (1984), expresión que ha propuesto invertir Joan Botella (1992) ya, que sin ser muy correcta gramaticalmente, describiria mejor el fenómeno del que quiere dar cuenta. 
; Ver la obra de PutNam, R., Making Democracy Work: Civic Traditions in Modern Italy, Princeton University Press, 1993; o la reciente edición de FedelE y LEONARDI, La politica senza i partiti, SEAM, Roma, 1996.

- Muy sugerente es la reflexión que se hace desde un, por así llamarlo, nuevo Derecho administrativo, que acepta una visión de la administración menos centrada en posiciones de supra/infraordenación, y que le preocupa la actividad no basada tanto en la imposición como guiada por la aceptabilidad social. de las soluciones. En L. Parejo, 1995, Eficacia y Administración, INAP, Madrid, p.150.

7 Ver CrozIer, M., 1995, La crise de l'intelligence. Essai sur l'impuissance des élites à se reformer, Intereditions, Paris. El INAP ha anunciado su pronta publicación en castellano.

${ }^{8}$ Ver Majone, G., 1995, Independence us. Accountability? Non-Majoritarian Institutions and Democratic Governance in Europe, paper European University Institute, mimeo.

9 Ver DaHL, R., 1992, - Why Free Markets Are Not Enough, en Journal of Democracy, número de julio, pp. 82-89.

10 Ver Subirats, J., 1995, .Policy Instruments, Public Deliberation and Evaluation Processes, en Dente, B. (ed.), Environmental Policy in Search of New Instruments, Kluwer, Dordrecht, pp. 143-158.

"Ver O'DonnelL, G., 1994, •Delegative Democracy• en Journal of Democracy, vol.5, n.1, enero, pp. $55-69$, en que se refiere especialmente a democracias instaladas recientemente como las de Argentina, Brasil, Perú, Ecuador, Bolivia, Filipinas, Corea o los paises poscomunistas europeos.

${ }^{12} \mathrm{Ver} \mathrm{Ch}$. Mouffe, 1995, -The End of Politics and the Rise of the Radical Right, en Dissent, pp. 498-502.

${ }^{13}$ En 1990, en Estados Unidos, se produjeron 67 referéndums sobre las más variadas cuestiones y en los más variados niveles, aprovechando la tradicional cita bianual del mes de noviembre. Vid. sobre este tema y sobre los problemas en combinar democracia representativa y deliberativa, J. FISHKIN, 1995, Democracia y deliberación, Ariel, Barcelona, pp. 95 y ss.

${ }^{14}$ Seguimos aquí la línea propuesta por John STEWART en el artículo ya citado anteriormente. is Ver al respecto, O. Renn, Th. Webler, H. Rakel, P. Dienel y B. Johnson, 1993, Public Participation in Decision Making: A Three-Step Procedure, en Policy Sciences, n.26, pp. 189-214; P.Dienel, 1989, •Contributing to Social Decision Methodology: Citizen Reports on Technological Projects en Ch. Vlek-G. Cretkovich (eds.), Social Decision Metbodology for Technological Projects, Kluwer, Dordrecht, pp. 133-151; H.HaRms, 1996, Respuestas a la crisis de la democracia representativa•, San Sebastián, mimeo.

16 Ver el libro ya mencionado de James Fistikin, donde incorpora numerosos ejemplos de uso de sus DOP o encuestas deliberativas.

${ }^{17}$ Citados en el artículo de J.STEWART ya mencionado.

18 Recogido de Stewart, Kendall y CoOTE, 1994, Citizens' Juries, Institute of Public Policy Research, Londres, p. 1.

19 Ver el trabajo de Fishín ya mencionado, p. 12. En relación a los experimentos de Fishkin en Gran Bretaña, sobre el concepto de crimen, y sobre el tema de Europa, ver The Economist, 17 de junio de 1995.

${ }^{20}$ Ver sobre el caso de Gran Bretaǹa, Joss, S. y Durant, J., Consensus Conferences, Science Museum, Londres.

${ }^{21}$ Ver al respecto Susskind, L. y CruikShank, J., 1987, Breaking the Impasse, Basic Books, New York, pp.56-57, o WEIDMER, H., 1995, AMediation as a Policy Instrument for Resolving Environmental Disputes. With Special Reference to Germany. en B.Dente (ed.), Environmental Policy in Search...op. cit., pp. 159-196.

22 Recientemente se publicó en The Economist, que los porcentajes de población que han ido apoyando en Gran Bretaña la permanencia de ese país en la Unión Europea han variado entre un $10 \%$ y un $60 \%$, básicamente debido a la forma en que se presentaba la cuestión a las personas interrogadas (ver el número de 17 de junio de 1995, p.23).

${ }^{23}$ Ver la publicación del Consejo de Europa sobre el tema: Local Referendums, Estrasburgo, 1994; o el trabajo de T. Cronin, 1989, Direct Democracy, Harvard University Press, Cambridge. A nivel de mesogobierno, ver el trabajo de D. B. MaGlFBY, Legislación Directa, en Limusa-Noriega Editores, Balderas-México, 1992, en relación a los referéndums estatales en los Estados Unidos.

${ }^{24}$ Ver la opinión del autor de Demosclerosis, Jonathan RAuCH, en la revista Time, 23 de enero de 1995 , p. 40. 